\title{
The Effect of Heat Treatment on the Microstructure and Properties of Explosively Welded Titanium-Steel Plates
}

\author{
Marcin Wachowski, Michał Gloc, Tomasz Ślęzak, Tomasz Płociński, and Krzysztof Jan Kurzydłowski
}

\author{
(Submitted June 18, 2016; in revised form October 25, 2016; published online February 6, 2017)
}

\begin{abstract}
This paper describes a study of explosively welded titanium-carbon steel S355J2+N plates. Following the welding, plates underwent heat treatment at temperature of $600^{\circ} \mathrm{C}$ for $90 \mathrm{~min}$ with cooling in furnace to $300{ }^{\circ} \mathrm{C}$ and in air to room temperature. The structure of the bonding was examined by using light, scanning electron (SEM) and transmission electron microscopy. The mechanical properties before and after heat treatment were examined applying three-point bending tests with cyclic loads and hardness measurements. Fracture surfaces were investigated using computer tomography and SEM. It has been found that the bonding areas are characterized by a specific chemical composition, microstructure and microhardness. Between the steel and the Ti cladding, a strongly defected transition zone was formed and melted areas with altered chemical composition were observed. It was also demonstrated that the heat treatment commonly applied to welded steel-Ti plates had a significant and negative impact on the microstructure and mechanical properties of the welded plates due to formation of brittle intermetallic phases.
\end{abstract}

Keywords cladding, explosive welding, joining, microstructure

\section{Introduction}

Protective coatings increase the strength, reliability and fatigue life of components made of mild steels. Some types of coatings require special welding or bonding methods, such as explosive bonding (Ref 1-3). This is a highly efficient technique used to join a wide variety of similar and/or dissimilar metals such as steel and titanium (Ref 4, 5). The main advantage of this process is the possibility to optimize the performance of the welded plates (Ref 6,7$)$ under the reduced diffusion of bonded metals. Another advantage is the possibility of joining elements of large sizes (maximum size of the sheet: $4 \times 7 \mathrm{~m}$ ) and of a wide range of base and cladding material thickness (Ref 8).

Microscopic investigations of the microstructure and mechanical properties of elements obtained by explosive welding have been reported in a number of papers (Ref 9-13). This has led to some simplifications in understanding of the properties of explosion welded plates (Ref 14, 15). The recent progress in scanning and transmission electron microscopy enables a more detailed investigation of the microstructure of the joints. The investigations, in turn, provide the results of the post-heat treatment of the welded plates, which is performed to relieve stresses and to reduce hardness, but, if improperly conducted,

Marcin Wachowski, Faculty of Mechanical Engineering, Military University of Technology, Warsaw, Poland; and Faculty of Materials Science and Engineering, Warsaw University of Technology, Warsaw, Poland; Michal Gloc, Tomasz Plociński, and Krzysztof Jan Kurzydłowski, Faculty of Materials Science and Engineering, Warsaw University of Technology, Warsaw, Poland; and Tomasz Ślęzak, Faculty of Mechanical Engineering, Military University of Technology, Warsaw, Poland. Contact e-mail: marcin.wachowski@ wat.edu.pl. may cause unfavorable changes in mechanical and structural properties of the material (Ref 16-19).

\section{Experimental Procedures}

The present study was conducted to study the microstructure and mechanical properties of explosively welded sheets of commercially pure titanium Grade 1 (ASME) plates with carbon steel S355J2+N (EN 10025). The plates dimensions were $500 \times 700 \mathrm{~mm}^{2}$ and thickness was $10 \mathrm{~mm}$. Cp-titanium sheet with thickness of $6 \mathrm{~mm}$ was used as a flyer plate. Chemical composition and mechanical properties of welded plates are listed in Tables 1 and 2. As an explosive, mixtures of ammonium nitrate fuel oil (ANFO) were used.

Metallographic observations were carried out using three samples cut from bimetal in the direction parallel to the joining surface. Samples were cut from the part of the plate opposite to the explosive initiation point. This part is removed prior to manufacturing of the final product. The samples were ground, polished using $0.6 \mu \mathrm{m} \mathrm{Al}_{2} \mathrm{O}_{3}$ powder and etched in lactic and nitric acid with hydrofluoric acid in distilled water solution as described in Ref 20. The microstructure of steel was revealed using nital (Ref 21). Metallographic observation of parent and flyer plates and the interface was carried out using a digital light microscope Keyence VHX-600. To examine chemical composition of the zone adjacent to the interface, scanning electron microscope (SEM) Hitachi SU-70 with energy-dispersive x-ray spectroscopy (EDS) and back-scattered electron (BSE) detector was used. TEM investigations were carried out on JEOL JEM1200 at $120 \mathrm{kV}$. Specimens were prepared using Hitachi dual beam (FIB/SEM) system. Microhardness measurements were taken across the joint boundary using Vickers tester with $100 \mathrm{~g}$ load and interval of $50 \mu \mathrm{m}$ in both the steel and titanium part. In order to define the mechanical properties before and after heat treatment, three-point bending tests with cyclic loads were carried out according to ASTM A263-94a standard (Ref 22). Specimen dimensions are shown in Fig. 1. Fracture surfaces 
Table 1 Chemical composition and mechanical properties of cp-titanium

\begin{tabular}{|c|c|c|c|c|c|c|}
\hline \multirow[t]{6}{*}{$\mathrm{cp}-\mathrm{Ti}$} & \multicolumn{6}{|c|}{ Chemical composition, mass $\%$} \\
\hline & $\mathrm{Fe}$ & $\mathrm{O}$ & $\mathrm{N}$ & $\mathrm{C}$ & $\mathrm{H}$ & $\mathrm{Ti}$ \\
\hline & 0.022 & 0.047 & 0.005 & 0.004 & 0.003 & Rest \\
\hline & \multicolumn{6}{|c|}{ Mechanical properties } \\
\hline & $\mathrm{R}_{0,2}$ & $\mathrm{R}_{\mathrm{m}}$ & A & E & & \\
\hline & $190 \mathrm{MPa}$ & $308 \mathrm{MPa}$ & $52 \%$ & $105 \mathrm{GPa}$ & & \\
\hline
\end{tabular}

Table 2 Chemical composition and mechanical properties of steel $\mathbf{S 3 5 5 J 2}+\mathrm{N}$

\begin{tabular}{|c|c|c|c|c|c|c|}
\hline \multirow[t]{5}{*}{$\mathrm{S} 355 \mathrm{~J} 2+\mathrm{N}$} & \multicolumn{6}{|c|}{ Chemical composition, mass $\%$} \\
\hline & $\mathrm{C}$ & $\mathrm{Si}$ & $\mathrm{Mn}$ & $\mathrm{P}$ & $\mathrm{S}$ & $\mathrm{Fe}$ \\
\hline & 0.193 & 0.350 & 1.480 & 0.013 & 0.003 & Rest \\
\hline & \multicolumn{6}{|c|}{ Mechanical properties } \\
\hline & $\begin{array}{c}\mathrm{R}_{0,2} \\
360 \mathrm{MPa}\end{array}$ & $\begin{array}{l}\mathrm{R}_{\mathrm{m}} \\
560 \mathrm{MPa}\end{array}$ & $\begin{array}{l}\text { A } \\
29 \%\end{array}$ & $\begin{array}{l}\mathrm{E} \\
192 \mathrm{GPa}\end{array}$ & & \\
\hline
\end{tabular}

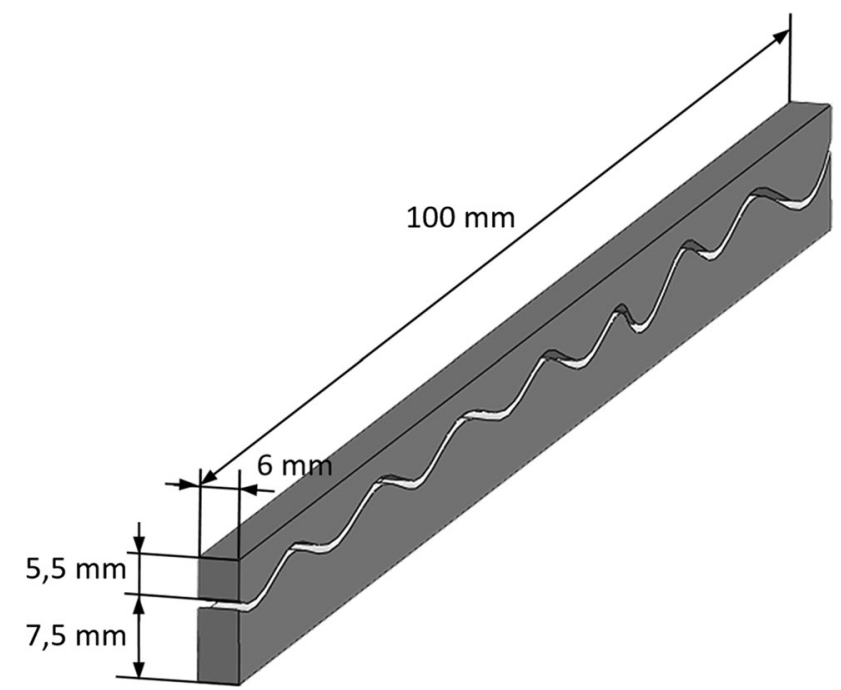

Fig. 1 Dimensions of the specimens used in three-point bending test

were investigated using computer tomography and SEM. Nanohardness measurements were taken using Hysitron TriboIndenter.

The post-welding heat treatment was performed at a temperature of $600{ }^{\circ} \mathrm{C}$ for $90 \mathrm{~min}$ with cooling at furnace to $300{ }^{\circ} \mathrm{C}$ and in the air to ambient temperature according to ASME UCS-56 Sector VIII (Ref 23).

\section{Results and Discussion}

\subsection{Microstructure of the Joint}

The microscopic observation focused on the representative areas in the distance from the edges which in explosively welded plates are removed prior to manufacturing of the final product. According to recent published research, wavelength and peak height of the wave are different depending on investigated places of the plate. Gradual change in wavelength along the direction of welding is observed due to change in impact angle. Interface near the explosive initiation point reveals flat morphology due to high angle of incidence while wavy interface is observed near the opposite edge of the plate (Ref 24-27). The microstructure examination of explosively welded plates titanium-carbon steel revealed wavy morphology of the joint surface in the part of the plate opposite to the explosive initiation point (Fig. 2), with an average distance between vertices of $727 \mu \mathrm{m}$ and the peak height of $86 \mu \mathrm{m}$. No delamination was found, which confirmed a well-conducted process of welding.

The microstructure of the steel plate revealed deformed grains elongated in the direction parallel to the joint (Fig. 3a) and along the propagation direction of the explosion wave. The deformed grains were observed both at the wave peaks and in the area between them. It was found that the degree of grain deformation increased with decreasing distance from the joint. The large plastic deformation resulted in a local increase in hardness. The steel plate microstructure at a distance larger than $200 \mu \mathrm{m}$ from the joint was characterized by pearlite and ferrite regions elongated parallel to the joint (Fig. 3b).

The microstructures in Fig. 3(c) and d show that the heat treatment has caused recrystallization of highly deformed grains and, in turn, hardness reduction. Recovery and grain growth were observed at the joint and at a farther distance into the steel plate. All these processes bring about a reduction in strain hardening. It has also been found that the annealing in the temperature of $600{ }^{\circ} \mathrm{C}$ for 90 min leads to decarburization of the area adjacent to the joint. This decarburization is the result of carbon diffusion into the joint.

Observations of the microstructure of the titanium plate revealed that changes induced by welding extended into a wider distance from the joint than in the steel plate.

Observations of the microstructure near to the bonding surface revealed adiabatic shear banding (ASB), which is a mechanism of plastic deformation in metals deformed at a high deformation rate (Fig. 4b) (Ref 28, 29). The ASBs were inclined at an angle of $45^{\circ}$ relative to the direction of detonation and had a length of approximately $500 \mu \mathrm{m}$. They were built of equiaxed grains approximately of $100 \mathrm{~nm}$ size and low dislocation density. 


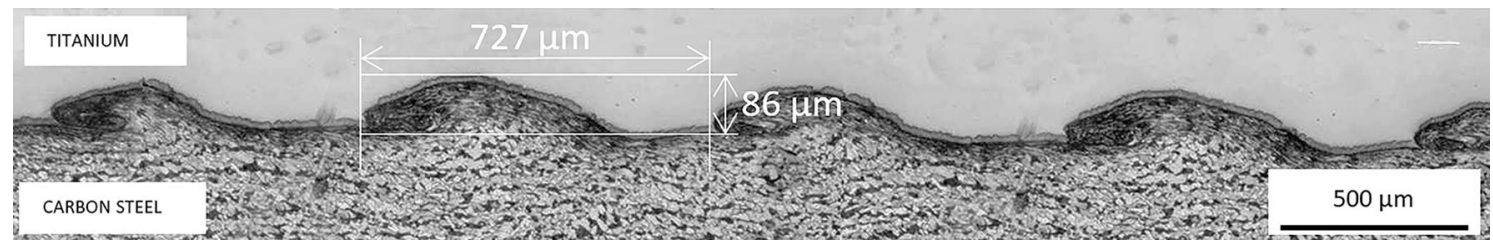

Fig. 2 Wavy morphology of the joint

(a)
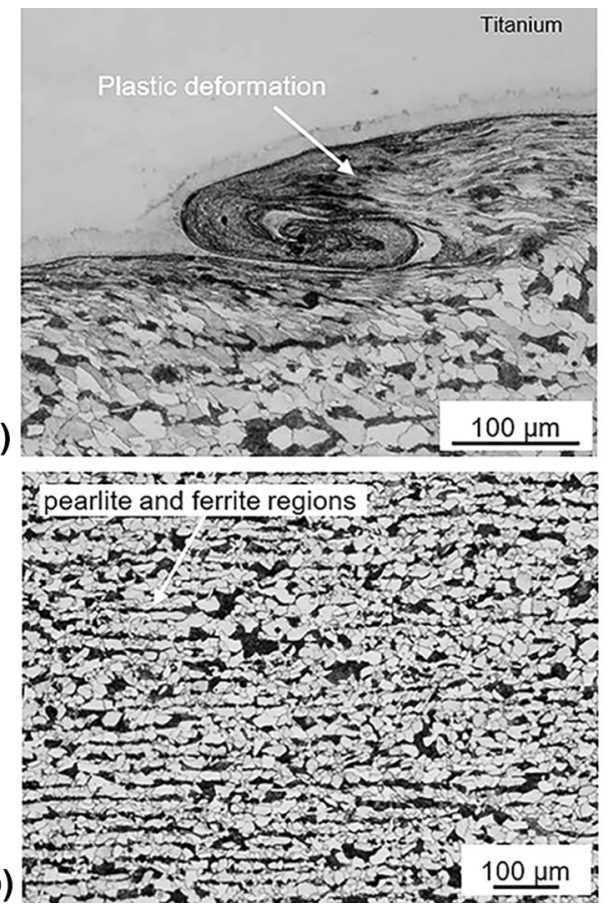
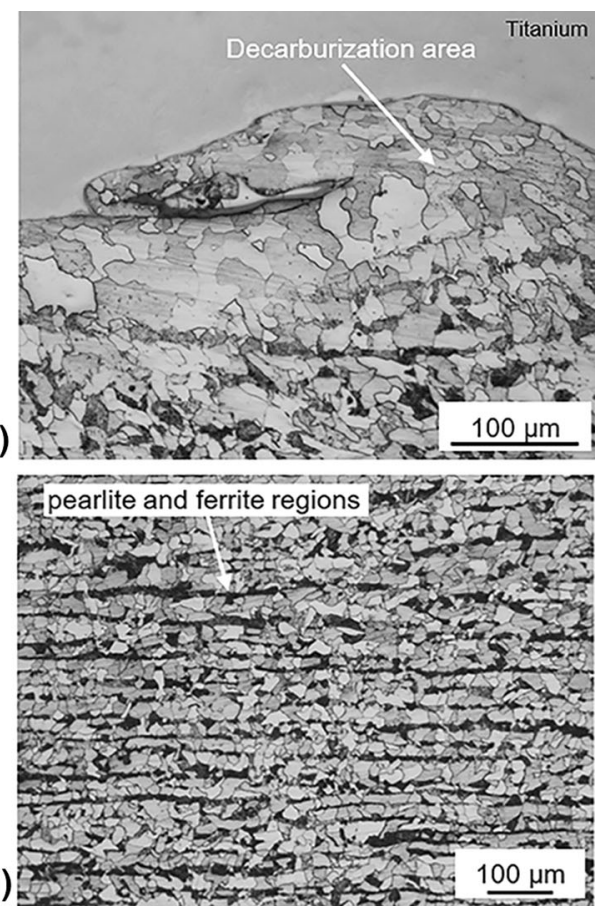

Fig. 3 Microstructure of steel [(a, b) before heat treatment; (c, d) after heat treatment]. (a, c) are taken in the region near the joint, while (b, d) are taken in the distance $1 \mathrm{~mm}$ from the joint

(a)
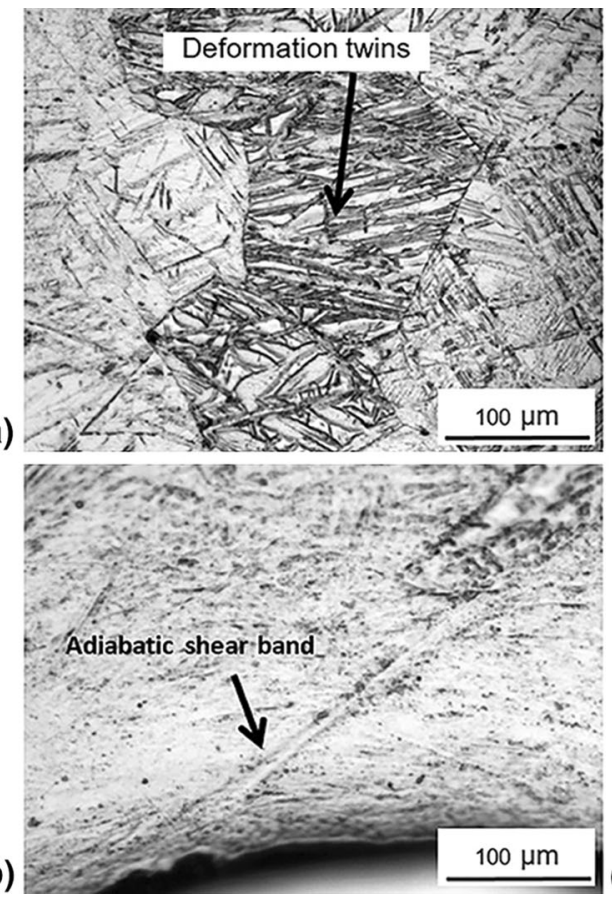

(c)
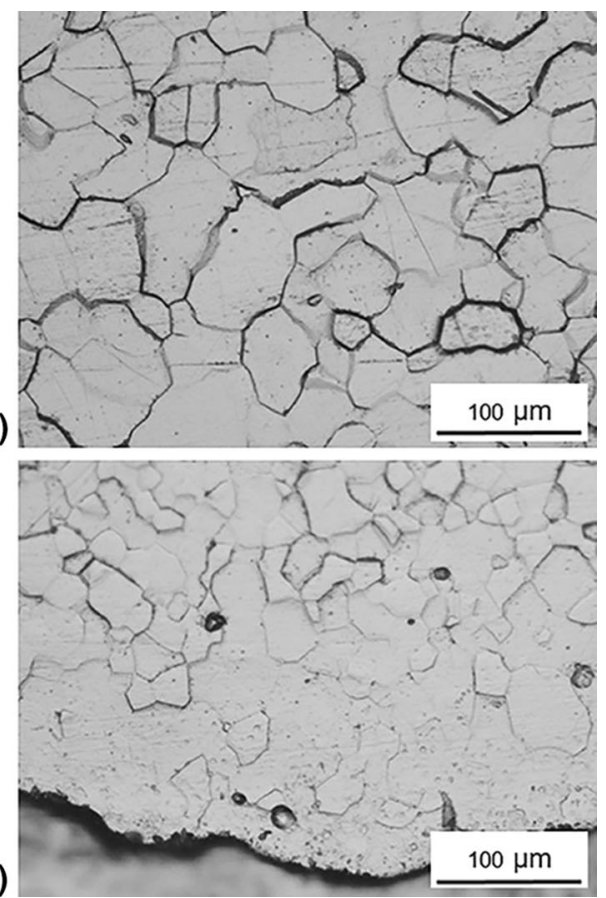

Fig. 4 Microstructures of titanium plate $[(a, b)$ before heat treatment; $(c, d)$ after heat treatment]. (b, d) are taken in the region near the joint, while $(\mathrm{a}, \mathrm{c})$ are taken in the distance $1 \mathrm{~mm}$ from the joint 
Since hexagonal titanium, unlike steel, does not have 12 independent slip systems, it has propensity for localization of plastic strain into ASBs. Further from the bond and next to the ASBs area, the microstructure of titanium features high density of deformation twins (Fig. 4a), which decreases with an increasing distance from the joint.

The results of observation revealed that the applied heat treatment brings about fine titanium particles located in the ASBs. Moreover, recrystallization process occurs, as shown in Fig. 4(c), leading to disappearance of adiabatic shear bands, formation of a homogeneous, equiaxed grains and reduction in hardness (Fig. 4d).

\subsection{Microstructure of the Joint: Vortexes}

Scanning electron microscopy before and after heat treatment revealed presence of melted areas (vortexes) in the bond zone. Melted areas in bimetallic plate are found in the inner parts of the undulations and in their front portions (Fig. 5).

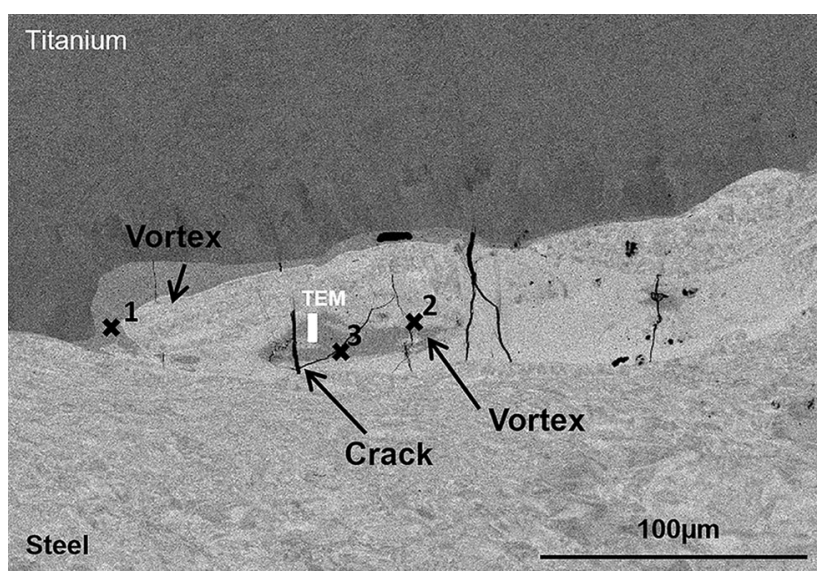

Fig. 5 SEM images of vortex structure before the heat treatment

Table 3 Chemical composition of the vortex before the heat treatment

\begin{tabular}{lccc}
\hline & \multicolumn{3}{c}{ Chemical composition, mol.\% } \\
\cline { 2 - 4 } Point & Ti & Mn & Fe \\
\hline 1 & 48.9 & 0.7 & 50.3 \\
2 & 31.3 & 1.2 & 67.5 \\
3 & 45.8 & 0.9 & 53.3 \\
\hline
\end{tabular}

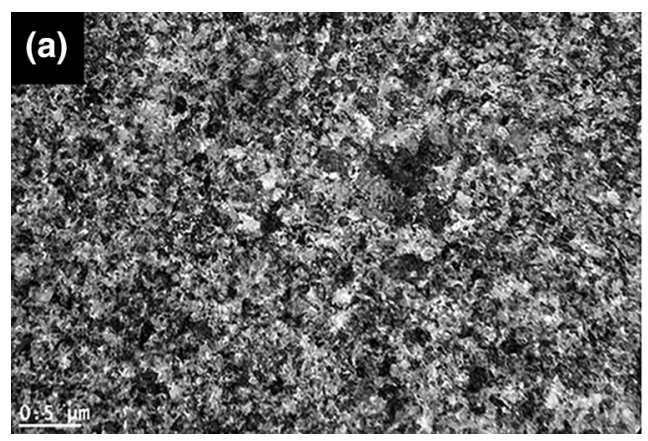

EDX results revealed presence of both titanium and iron (Table 3 ). The ratio of iron to titanium varies across the melted areas, as shown in Fig. 5 using a gray scale contrast. The measured chemical compositions indicate possible presence of FeTi and $\mathrm{Fe}_{2}$ Ti phases. However, the particles imaged in Fig. 6 in a bright-field contrast generate diffraction patterns which do not fit to those of $\mathrm{FeTi}$ and $\mathrm{Fe}_{2} \mathrm{Ti}$. In fact, these patterns diverge from any data for intermetallic phases, indicating the presence of inclusions. TEM investigations revealed ultrafine grains in

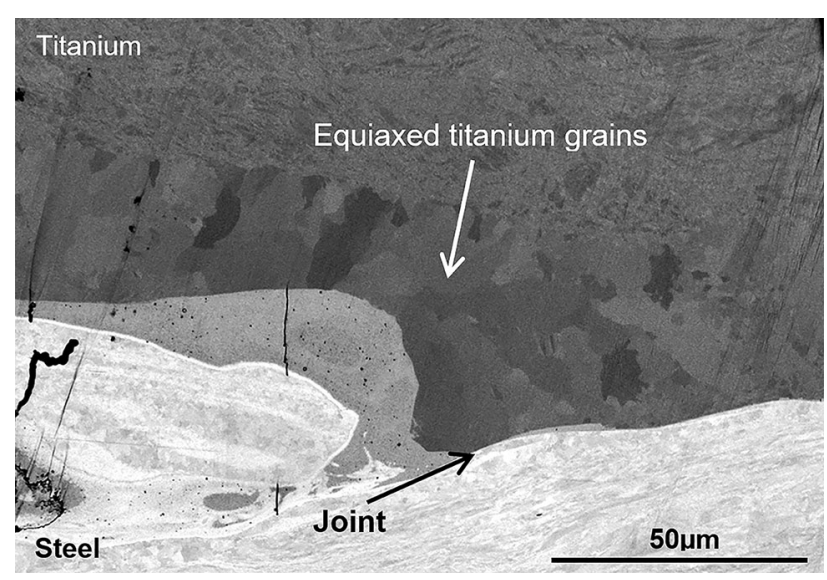

Fig. 7 Microstructure of titanium near the joint—material before heat treatment

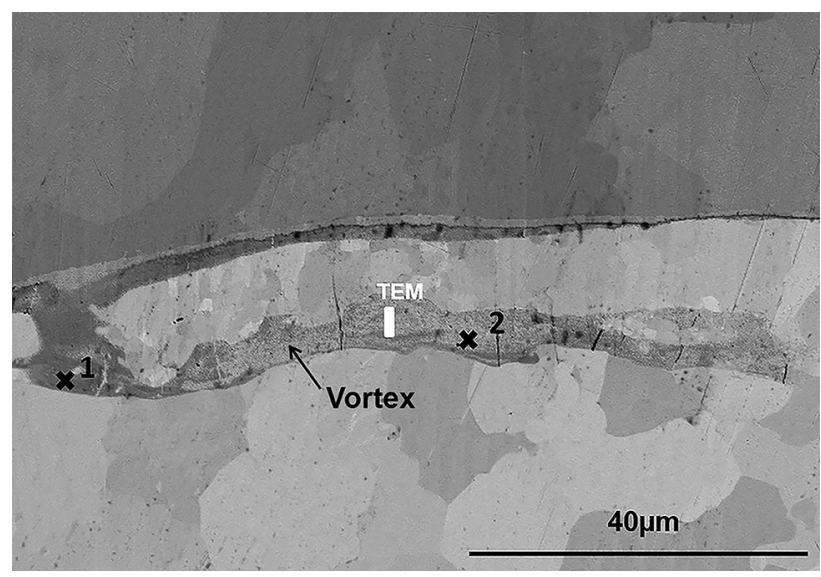

Fig. 8 SEM images of vortex after the heat treatment

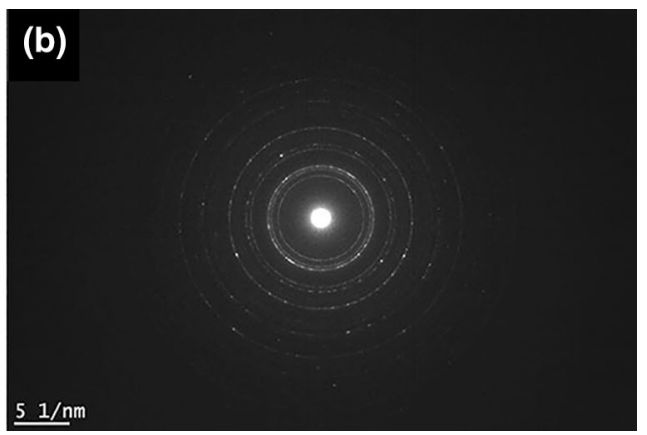

Fig. 6 TEM images and diffraction pattern of the vortex before heat treatment [(a) bright field, (b) diffraction pattern]. TEM lamella position at Fig. 5 
Table 4 Chemical composition of vortex after the heat treatment

\begin{tabular}{lccc}
\hline & \multicolumn{3}{c}{ Chemical composition \% weight } \\
\cline { 2 - 4 } Point & Ti & Mn & Fe \\
\hline 1 & 47.3 & 1.4 & 51.4 \\
2 & 37.0 & 0.9 & 62.1 \\
\hline
\end{tabular}

the microstructure of the vortexes. Furthermore, some microcracks were observed.

The higher-resolution observations revealed a characteristic zone between the joint and the ASBs area, with equiaxed grains of titanium (Fig. 7). The thickness of this zone was approximately $35 \mu \mathrm{m}$, while the grain size was approximately $7 \mu \mathrm{m}$.

As could be expected, the heat treatment did not change profoundly the chemical composition of the vortexes and their morphology (Fig. 8). However, it increased measurably their
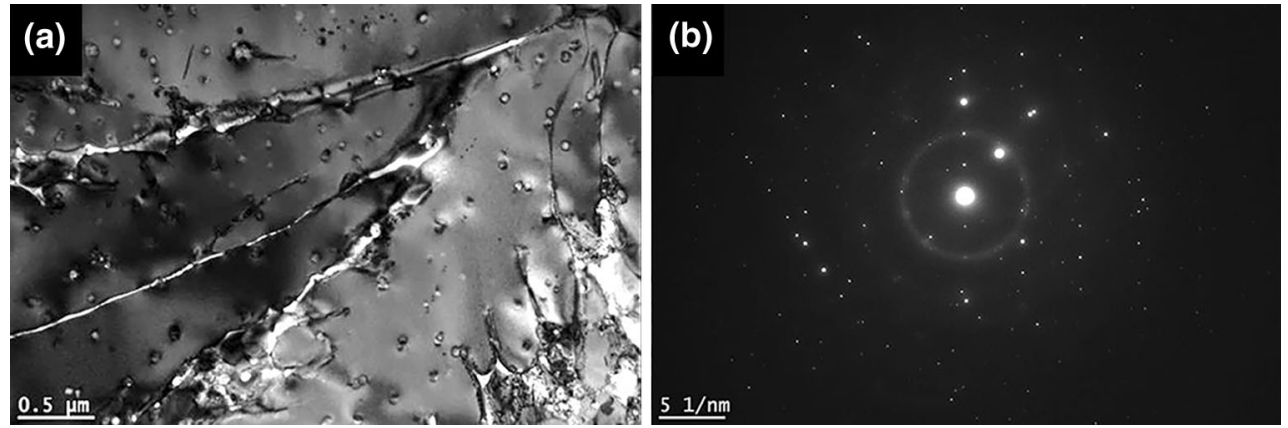

Fig. 9 TEM images and diffraction pattern after the heat treatment [(a) bright field, (b) diffraction pattern]. TEM lamella position at Fig. 8
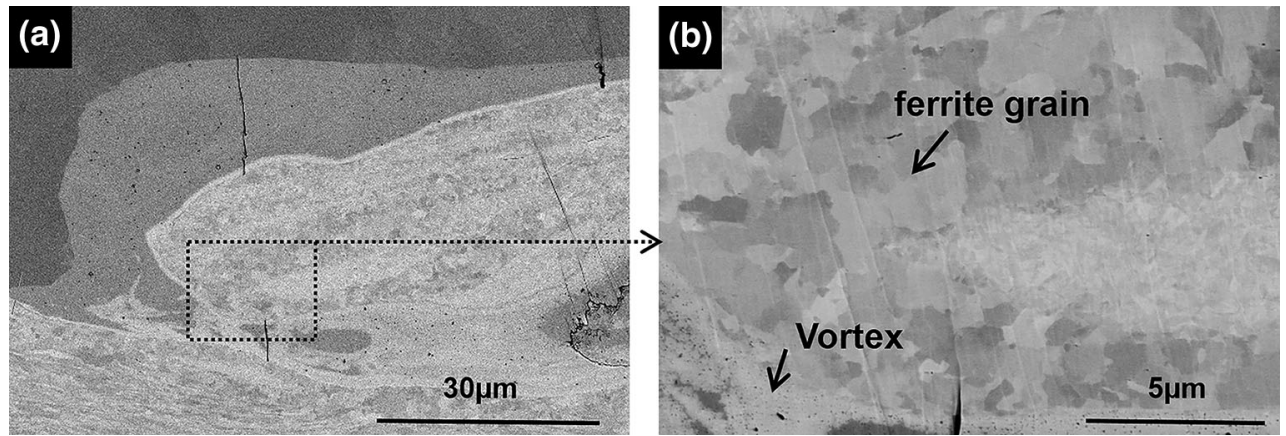

Fig. 10 Microstructure of steel around vortex before the heat treatment

(a)

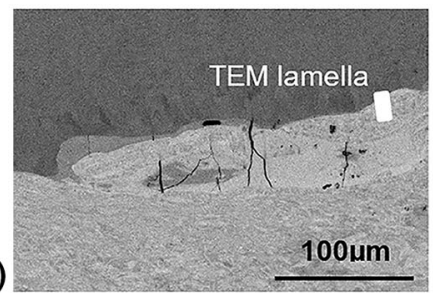

(b)

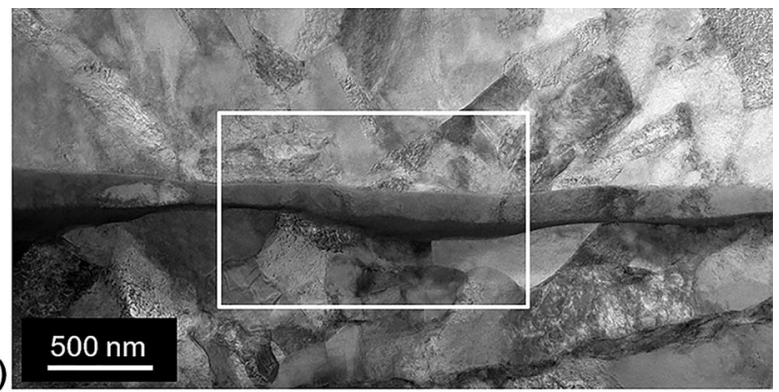

(c)
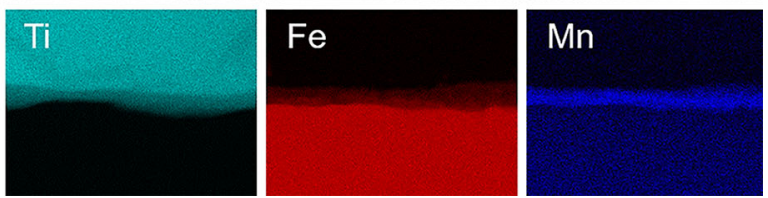

Fig. 11 TEM investigations of a transition zone - material before heat treatment [(a) place of cutting TEM lamella, (b) microstructure of transition joint of bimetal in state before heat treatment, (c) EDX mapping] 
size because of the diffusion taking place during the annealing. The chemical and structural composition of the vertexes did not change-see Table 4 and Fig. 8. Generated diffraction patterns (Fig. 9b) do not fit to those of FeTi and Fe2Ti.

Local melting of the joined plates takes place under high energy released by the explosion, high pressure and a temperature rise under adiabatic conditions. The melting is followed by fast cooling $\left(10^{5}-10^{7} \mathrm{~K}\right)$ and high rate crystallization, which results in formation of metastable phases of high hardness $>700 \mathrm{HV}$. Fast cooling also results in thermal stresses leading to void formation and microcracking (Fig. 5, 8 ). The melted zones are surrounded by recrystallized ferrite grains (Fig. 10), which are a result of heat exchange between vortex and plastically deformed base material.

\subsection{Microstructure of the Joint: Transition Zone}

Scanning and transmission electron microscopic investigations revealed specific features of the transition zone between the joined plates. The sample representative for the zone is shown in Fig. 11(a), and the microstructure is illustrated in Fig. 11(b). The zone contains a mixture of base and flyer material. Its characteristic feature is an increased content of manganese as compared to the surrounding materials (Fig. 11c). This is due to diffusion of the elements during formation of the bond, and it proves the thermodynamic character of the bond formation mechanism.

The features of the transition zone after the heat treatment are shown in Fig. 12(b). Fine precipitates of alpha iron $(\alpha-F e)$ and titanium carbide (TiC) in the matrix of titanium were identified in the diffraction patterns shown in Fig. 12(c). A growth of the transition zone in the titanium direction after heat treatment was observed.

The mechanism of formation of a transition joint can be described as a thermodynamic process. The changes in Gibbs free energy $\Delta G$ for $\mathrm{TiC}, \mathrm{Fe}_{3} \mathrm{C}, \mathrm{Fe}_{2} \mathrm{Ti}$ and $\mathrm{FeTi}$ as a function of temperature are shown in Fig. 13 (Ref 30, 31). The lowest value of $\Delta G$ is for formation of $\mathrm{TiC}$ in the temperature range of $1000-2000 \mathrm{~K}$, which is the temperature generated at the impact point (Ref 32). From the Ti-C phase diagram, it can be

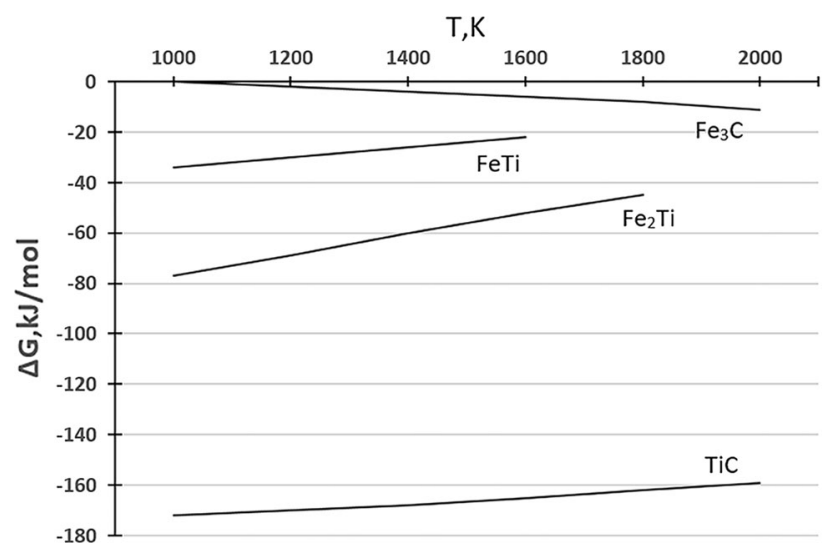

Fig. 13 Variation of change in Gibbs free energy of possible reactions within the Fe-Ti-C system as a function of temperature (Ref 34-36) (a)

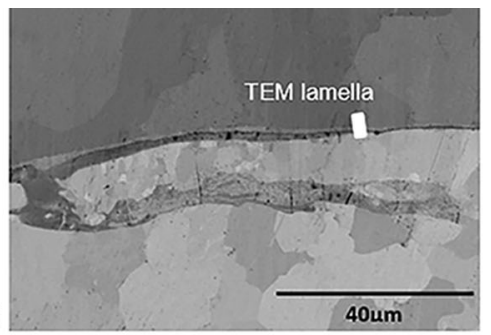

(b)
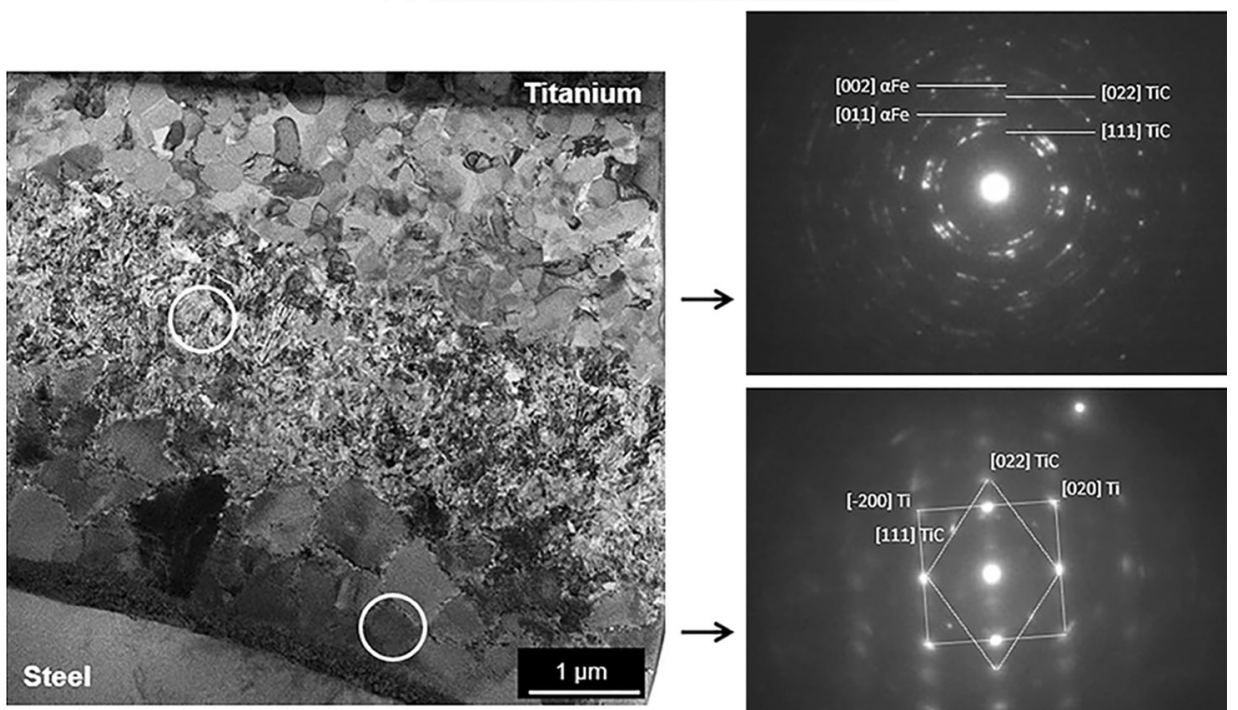

(c)

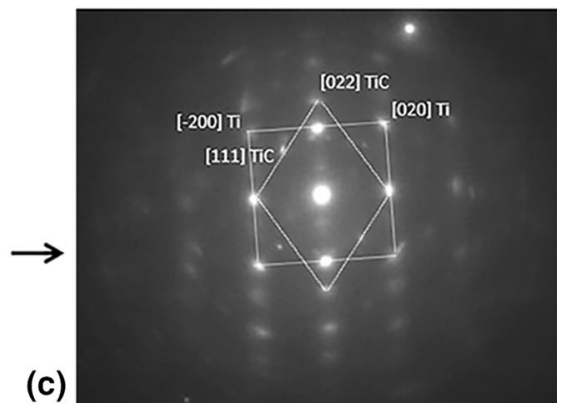

Fig. 12 TEM investigation of transition zone - material after heat treatment [(a) place of cutting TEM lamella, (b) microstructure of transition joint of bimetal in state after heat treatment, (c) indexed diffraction patterns] 


\begin{tabular}{|c|c|c|c|c|c|c|c|c|}
\hline \multirow{3}{*}{$\begin{array}{l}\text { Bending moment, Nm } \\
48\end{array}$} & \multicolumn{4}{|c|}{ Before heat treatment } & \multicolumn{4}{|c|}{ After heat treatment } \\
\hline & \multicolumn{3}{|c|}{ Fatigue life, $\mathbf{N f}$} & \multirow{2}{*}{$\begin{array}{c}\text { Average value } \\
2,000,000\end{array}$} & \multicolumn{3}{|c|}{ Fatigue life, Nf } & \multirow{2}{*}{$\begin{array}{c}\text { Average value } \\
2,000,000\end{array}$} \\
\hline & $2,000,000$ & $\ldots$ & $\ldots$ & & $2,000,000$ & $\cdots$ & $\ldots$ & \\
\hline 60 & $2,000,000$ & $\ldots$ & $\ldots$ & $2,000,000$ & $2,000,000$ & $\ldots$ & $\ldots$ & $2,000,000$ \\
\hline 72 & $2,000,000$ & $2,000,000$ & $2,000,000$ & $2,000,000$ & $2,000,000$ & $1,574,700$ & $2,000,000$ & $1,858,233$ \\
\hline 84 & 348,500 & 863,800 & 749,900 & 654,067 & 283,300 & 218,400 & 135,700 & 212,467 \\
\hline 96 & 277,000 & 360,150 & 332,600 & 323,250 & 178,300 & 115,300 & 102,900 & 132,167 \\
\hline 108 & 100,300 & 148,850 & 219,650 & 156,267 & 46,900 & 43,800 & 48,400 & 46,367 \\
\hline 120 & 34,900 & 118,100 & 58,850 & 70,617 & 25,670 & 22,280 & 32,300 & 26,750 \\
\hline
\end{tabular}

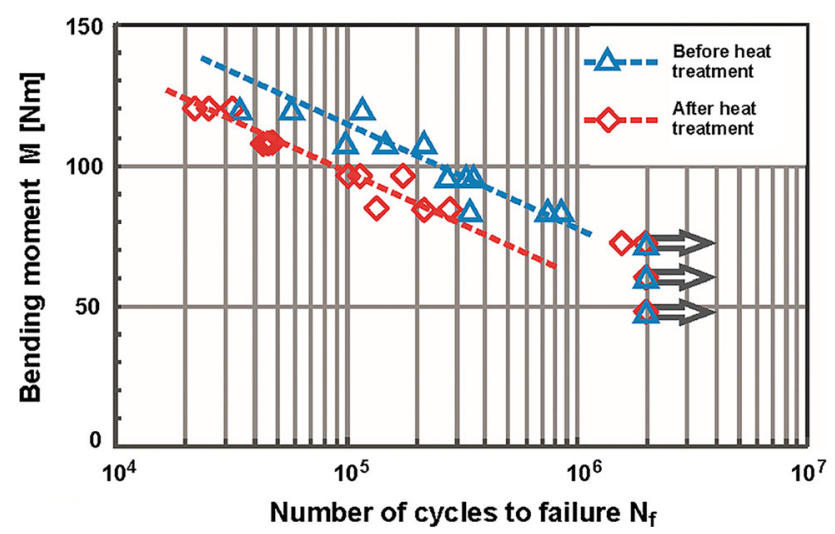

Fig. 14 Influence of heat treatment on fatigue behavior of examined material

concluded that $\mathrm{TiC}_{x}$ exists as a carbide phase with stoichiometry from $X=0.47$ to 0.98 . $X$ value depends on the C/Ti ratio of raw material. Higher $X$ value corresponded to higher C/Ti ratio. But in the case of explosively welded Ti-steel bond, there is also the possibility of formation of $\mathrm{Fe}_{2} \mathrm{Ti}$, FeTi and $\mathrm{Fe}_{3} \mathrm{C}$. $\mathrm{Fe}_{2} \mathrm{Ti}$ phase forms when the $\mathrm{C} / \mathrm{Ti}$ ratio is too low and the carbon content is insufficient to react with titanium to form $\mathrm{TiC}$ or $\mathrm{TiC}_{x}$ (Ref 33).

\subsection{Fatigue Behaviors}

A three-point bending flexural test was performed to determine the effect of the microstructure on the fatigue strength under flexural stresses. The fatigue tests were carried out under the loading asymmetry cycle coefficient $R=0.1$ and frequency of $20 \mathrm{~Hz}$. The definition of failure was the complete rupture of titanium plate. The infinite fatigue life of $2 \times 10^{6}$ cycles was established. The results of the tests are presented in Table 5.

On the basis of the results, a graph of fatigue life was prepared, shown in Fig. 14. This graph shows a negative influence of heat treatment on the fatigue performance of the investigated bimetallic plates. The heat treatment has caused approximately $20 \%$ decrease in fatigue strength (in our case defined by bending moment) across the whole range of fatigue life.

\subsection{Microhardness}

Microhardness measured for the bimetallic plate before the heat treatment is shown in Fig. 15. It was found that local strengthening occurred in the joint to a distance of approximately $200 \mu \mathrm{m}$ into the steel. Maximum microhardness was measured near to the joint in the steel plate $\left(\mathrm{HV}_{0,1}=297\right)$. Nanohardness test indicated the hardness of transition zone of approximately $13.21 \mathrm{GPa}$. At a distance larger than $200 \mu \mathrm{m}$ from the joint into the steel, hardness reaches the value of the base material.

After the heat treatment, a reduction in hardness in the bond area was observed due to decarburization of steel in this zone $\left(\mathrm{HV}_{0,1}=134\right)$. The hardness of intermetallic inclusions in the transition joint was reduced to $6.11 \mathrm{GPa}$. In the case of titanium, the heat treatment also reduced hardness due to the process of recovery, recrystallization and annihilation of adiabatic shear bands.

\subsection{Fracture Surface Analysis}

Observations of fracture surfaces were carried out to assess the influence of heat treatment on the mechanism of crack propagation. SEM images in Fig. 16 show the fracture surface of titanium plates in samples subjected to fatigue under a bending moment of $96 \mathrm{Nm}$ before (column "a") and after (column " $b$ ") the heat treatment. The front of the crack in the samples before the heat treatment (Fig. 16a) was more regular. The crack stopped at a distance of approximately $0.5 \mathrm{~mm}$ from the joint before the final damage. After the heat treatment (Fig. 16b), the cracking was irregular with no restraining effect near the joint.

At the crack initiation stage (Fig. 16a-I and b-I), fissure-type striations (FS) and striation-like marking (SM) can be noticed. Figure 16(a-I) illustrates the crack blocking at grain boundaries (B) and deformation twins (T), not observed after HT. At the stages of stable crack growth (Fig. 16a-II and b-II) and unstable cracking (Fig. 16 a-III and b-III), dislocation slip (S) with accompanying twinning $(\mathrm{T})$ takes place. Numerous microcracks at the junction of slip bands (MC) and secondary cracks (SC) were also observed.

Interesting results were obtained during examination of the surface of the joint after delamination (Fig. 16a-IV and b-IV). The specimen before the heat treatment revealed a wavy morphology of the joint. After the treatment, this feature was also observed. Differences in wave dimensions in Fig. 16(a-IV and $16 \mathrm{~b}$-IV) are due to different locations of investigated samples.

In order to investigate the crack propagation, a computed tomography was used. The investigated samples were fatigued until the main crack appeared but before the delamination of the joint. The images obtained are shown in Fig. 17. 


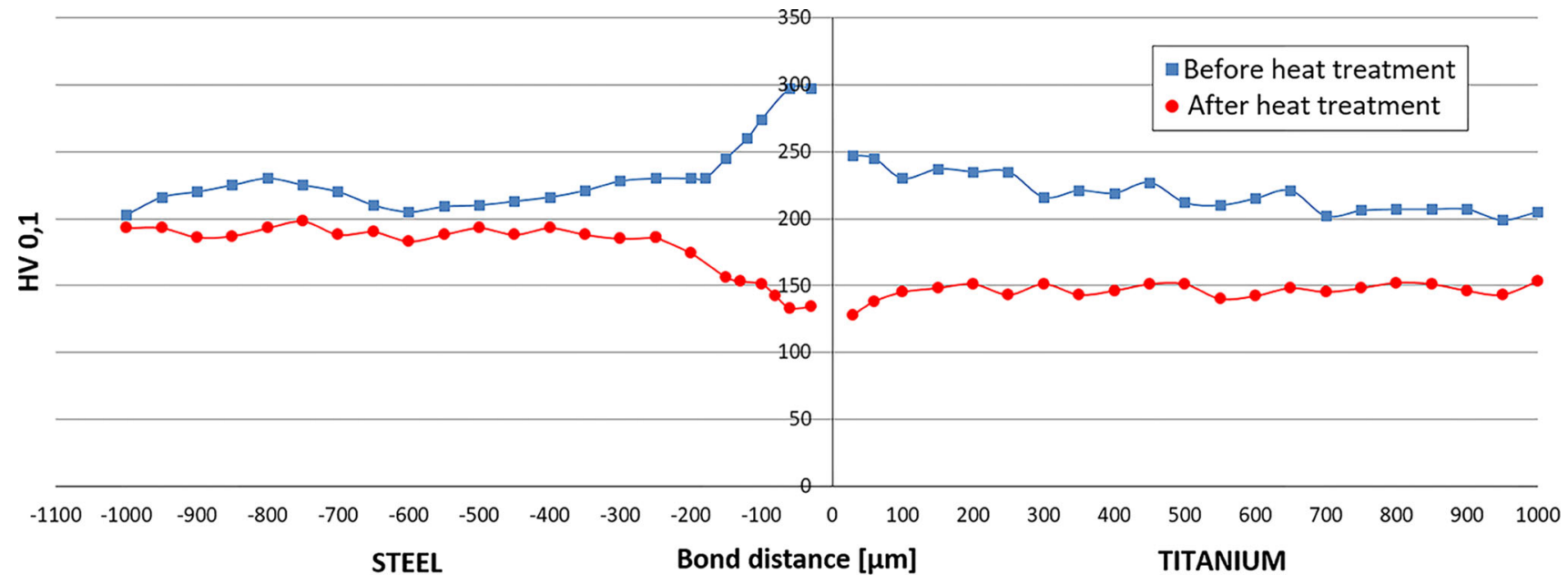

Fig. 15 Microhardness profile for explosively welded bimetal in state before and after the heat treatment

(a)

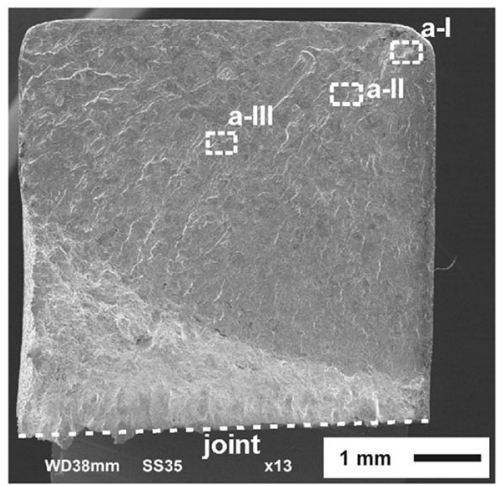

(a-I)
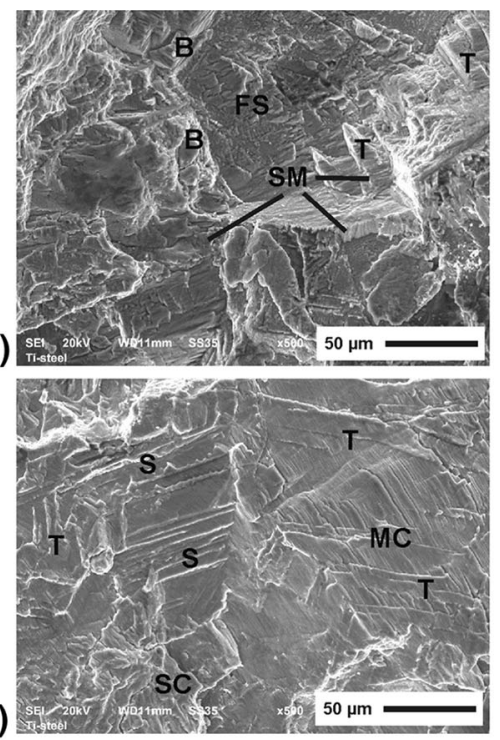

(a-III)

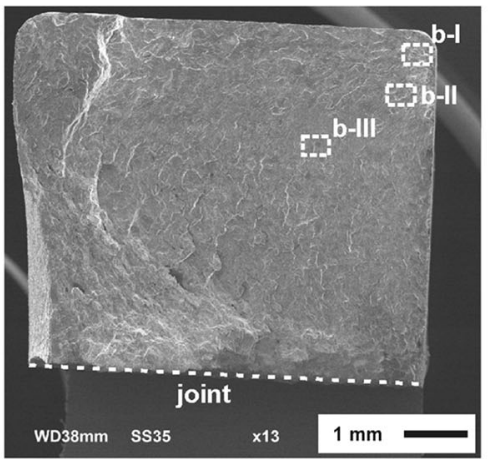

(b-I)
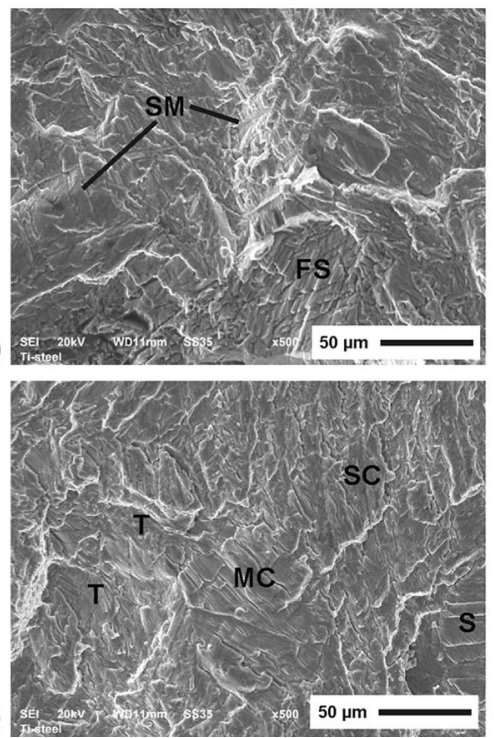

(a-II)
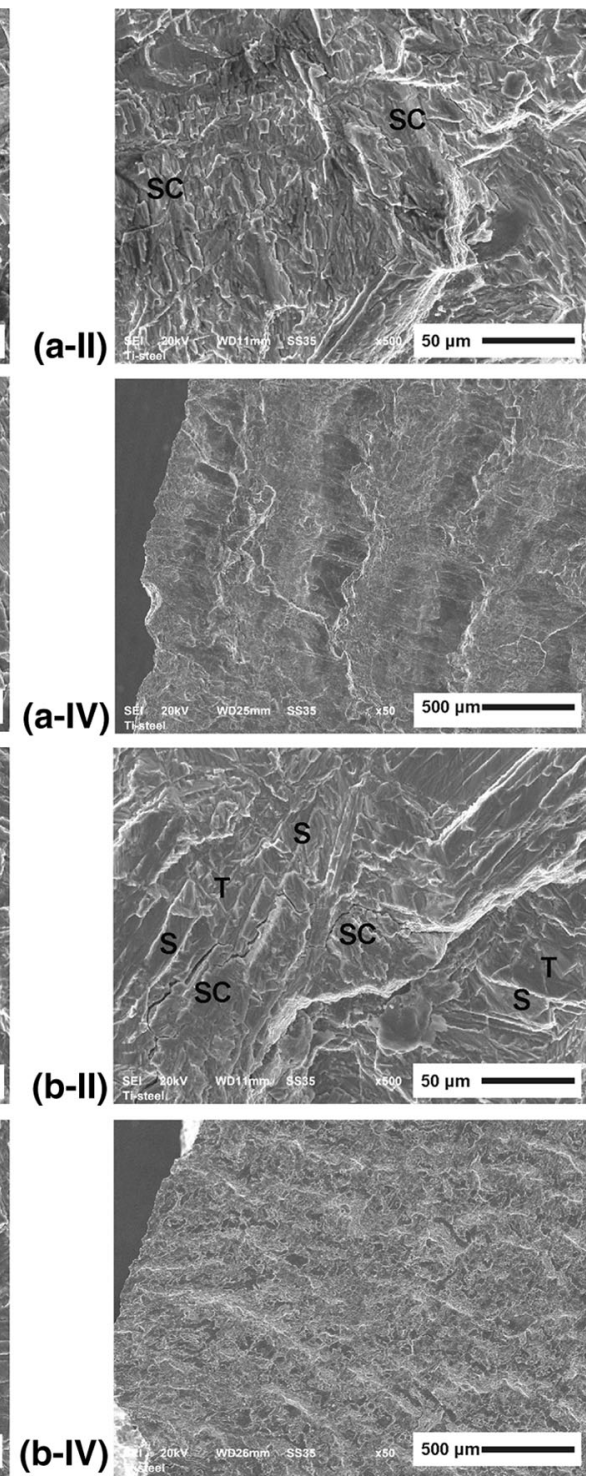

(b-III)

Fig. 16 SEM images of the fracture surfaces in the specimens tested under $96 \mathrm{Nm}$ before (a) and after heat treatment (b) 


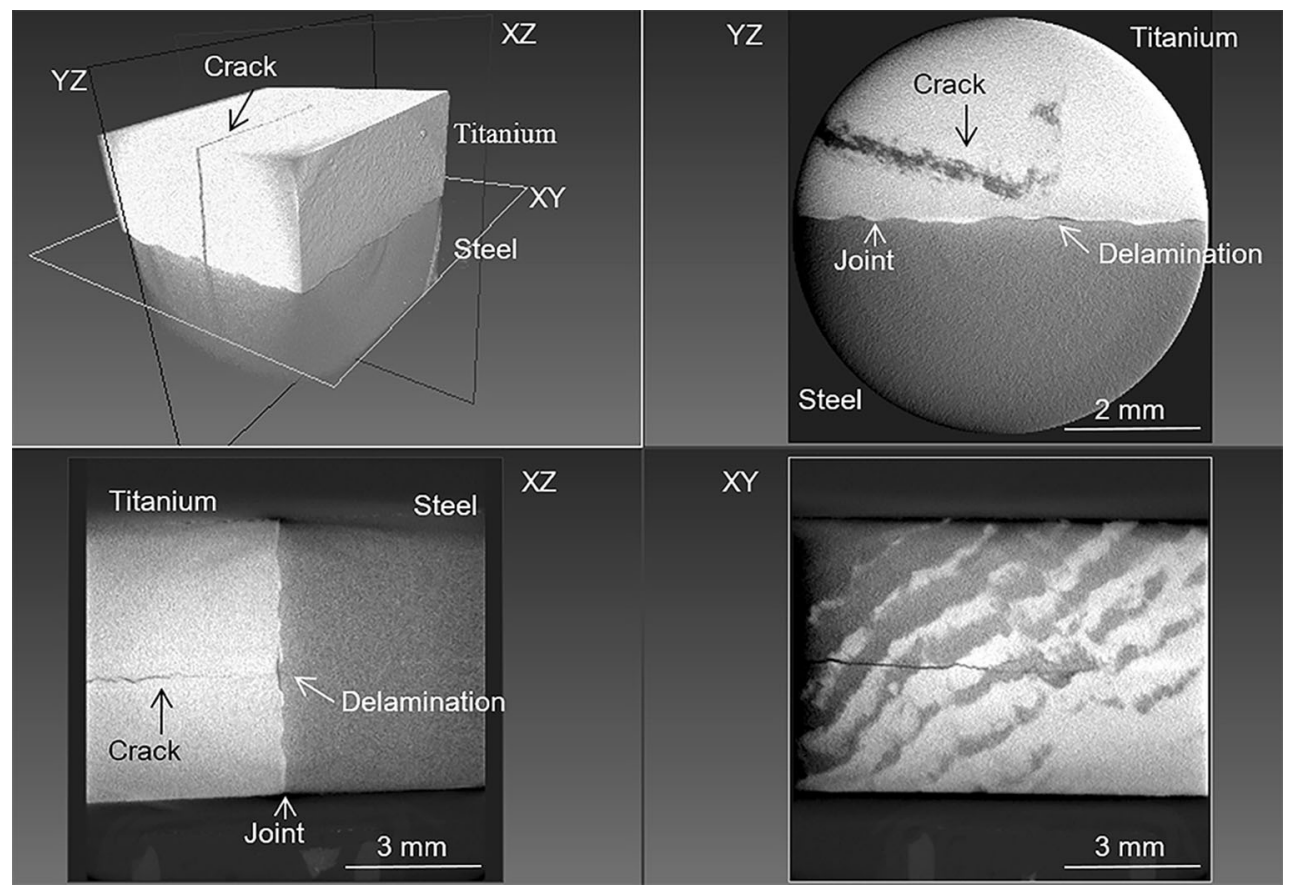

Fig. 17 Images computed with an x-ray computer tomography

Delamination of the joint took place under the effect of the crack, which propagated from the corner of the titanium side toward the joint, in agreement with the fact that maximum stresses occur at some distance from the front of the propagating crack.

\section{Conclusions}

The analysis of the results shows that explosive welding results in diffusion of elements under the influence of high stress. Local plastic deformation of the joined plates and high temperature enable achievement of high adhesion. Diffusion and recrystallization during the bonding lead to formation of a transition layer in the joint. The time of bonding is short and the impact zone between the materials is small. Simultaneously, the cooling rate reduces the formation of intermetallic phases to a minimum.

The microstructure of the joint is characterized by the presence of areas containing remelted and solidified titanium with some content of iron and metastable phases. The heat treatment used in the study increases the relative volume of intermetallic phases. Moreover, it causes a reduction in fatigue strength of the joint.

\section{Acknowledgments}

This work was supported by the National Centre for Research and Development as part of Project NR-15-0038-10/2010.

\section{Conflict of interest}

The authors declare that they have no conflict of interest.

\section{Open Access}

This article is distributed under the terms of the Creative Commons Attribution 4.0 International License (http://creativecom mons.org/licenses/by/4.0/), which permits unrestricted use, distribution, and reproduction in any medium, provided you give appropriate credit to the original author(s) and the source, provide a link to the Creative Commons license, and indicate if changes were made.

\section{References}

1. K. Karolczuk, K. Kluger, M. Kowalski, F. Żok, and G. Robak, Residual Stresses in Steel-Titanium Composite Manufactured by Explosive Welding, Mater. Sci. Forum, 2012, 726, p 125-132

2. L. Č́žžek, D. Ostroushko, E. Mazancová, Z. Szulc, R. Molak, M. Wachowski, and M. Prażmowski, Structure and Properties of Sandwich Material Steel Cr13Ni10 + Ti After Explosive Cladding, Metall. J., 2009, 62(6), p 110-112

3. P. Tamilchelvan, K. Raghukandan, K. Hokamoto, H.C. Dey, and A.K. Bhaduri, Effect on Explosive Cladding of Titan 12/SS304L Plates Under Multiple Conditions (Design Matrix), Mater. Sci. Forum, 2004, 465-466, p 207

4. D. Cutter, What You Can Do with Explosion Welding, Weld. J., 2006, 6, $\mathrm{p} 40$

5. F. Findik, Recent Developments in Explosive Welding, Mater. Des., 2011, 32, p 1081-1093

6. G.A. Young, J.G. Banker, in Explosion Welded Bi-Metallic Solutions to Dissimilar Metal Joining, 13th Offshore Symposium, February (2004), Houston, Texas

7. J.M. Stone, Applications of explosion-bonded clads, in Conference on Explosive Welding, September (1968), Hove

8. A. Joshi, Introduction to Explosive Welding (Dept. of Metallurgical Engineering \& Material Science, Indian Institute of Technology, Bombay, 2000)

9. M. Tršo, M. Benák, M. Turňa, P. Nesvadba, Structural stability of composite materials prepared by explosion welding after their heat treatment, in Defect and Diffusion Forum (2010), pp. 297-301 
10. R. Kacar and M. Acarer, An Investigation on the Explosive Cladding of 316L Stainless Steel-din-P355GH Steel, J. Mater. Process. Technol., 2004, 152, p 91-96

11. S.A.A. Akbari Mousavi, S.T.S. Al-Hassani, and A.G. Atkins, Bond Strength of Explosively Welded Specimens, Mater. Des., 2008, 29, p 1334-1352

12. A. Durgutlu, B. Gülenç, and F. Findik, Examination of Copper/ Stainless Steel Joints Formed by Explosive Welding, Mater. Des., 2005, 26, p 497-507

13. S. Kundu, D. Roy, S. Chatterjee, D. Olson, and B. Mishra, Influence of Interface Microstructure on the Mechanical Properties of Titanium/17-4 PH Stainless Steel Solid State Diffusion Bonded Joints, Mater. Des., 2012, 37, p 560-568

14. L. Čižek, D. Ostroushko, Z. Szulc, R. Molak, and M. Prażmowski, Properties of Sandwich Metals Joined by Explosive Cladding Method, Arch. Mater. Sci. Eng., 2010, 43, p 21-29

15. V. Phillipchuk, Explosive welding status, ASTME Creative Manufacturing Seminar (1961), pp. 65-100

16. V. Hutsaylyuk, V. Hlado, A. Sobhak, M. Blavitskyi, Degradation structure of steel $12 \mathrm{Kh} 1 \mathrm{MF}$ of the collector of super-heater, in 14th International Conference on Transport Means, October 2010, Lithuania

17. S. Król, Heat Treatment of Explosively Welded Bimetallic Clad Materials, Weld. Int., 1991, 5(12), p 944-948

18. E.A. Prikhodko, I.A. Bataev, V.S. Lozhkin, V.I. Mali, M.A. Esikov, The Effect of Heat Treatment on the Microstructure and Mechanical Properties of Multilayered Composites Welded by Explosion, $A d v$. Mater. Res., 2012, 535-537, p 231-234

19. D. Ostroushko and E. Mazancova, Chosen Properties of Sandwich Material Ti-304L Stainless Steel After Explosive Welding, Mater. Eng., 2011, 18, p 8-10

20. P. Tamilchelvan, K. Raghukandan, K. Hokamoto, H.C. Dey, and A.K. Bhaduri, Effect on Explosive Cladding of Titan 12/SS304L Plates Under Multiple Conditions (Design Matrix), Mater. Sci. Forum, 2004, 465-466, p 207

21. R. Kacar and M. Acarer, Microstructure-Property Relationship in Explosively Welded Duplex Stainless Steel-Steel, Mater. Sci. Eng., A, 2003, 363, p 291

22. ASTM A263-94a, Standard Specification for Corrosion-Resisting Chromium Steel-Clad Plate, Sheet, and Strip
23. ASME Section VIII Div. 1 Part UCS-56 (Requirements for Pressure Vessels Constructed of Carbon and Low Alloy Steels)

24. S.K. Godunov, A.A. Deribas, and N.S. Kozin, Wave Formation in Explosive Welding, J. Appl. Mech. Tech. Phys., 1973, 12(3), p 398-406

25. A.A.A. Mousavi and S.T.S. Al-Hassani, Numerical and Experimental Studies of the Mechanism of the Wavy Interface Formations in Explosive/Impact Welding, J. Mech. Phys. Solids, 2005, 53(11), p 2501-2528

26. E. Carton, Wave Forming Mechanisms in Explosive Welding, Mater. Sci. Forum, 2004, 465-466, p 219-224

27. S.R. Reid, A Discussion of the Mechanism of Interface Wave Generation in Explosive Welding, Int. J. Mech. Sci., 1974, 16(6), p 399IN4401-400IN5413

28. B.F. Wang, Y. Yang, Z.P. Chen, and Y. Zeng, Adiabatic Shear Bands in $\alpha$-Titanium Tube Under External Explosive Loading, J. Mater. Sci., 2007, 42, p 8101-8105

29. B.F. Wang, Y. Yang, Distribution and Dynamic Propagation of Adiabatic Shear Bands on the Titanium Side in the Titanium/Mild Steel Explosive Cladding Plate, Mater. Sci. Eng. A, 2007, 452-453, p 273-277

30. Y.J. Liang and Y.C. Che, Thermodynamic Data Handbook of Inorganic Substances, Northeastern University Press, Shenyang, 1994, p 328

31. I. Barin, O. Knacke, and O. Kubaschewski, Thermochemical Properties of Inorganic Substances, Springer, Berlin, 1977, p 257-258

32. T. Wang, T. Ivas, C. Leinenbach, and J. Zhang, Microstructural Characterization of $\mathrm{Si} 3 \mathrm{~N} 4 / 42 \mathrm{CrMo}$ Joint Brazed with $\mathrm{Ag}-\mathrm{Cu}-$ Ti + TiNp Composite Filler, J. Alloy. Compd., 2015, 651, p 628

33. Z. Mei, Y.W. Yan, and K. Cui, Effect of Matrix Composition on the Microstructure of In Situ Synthesized TiC Particulate Reinforced IronBased Composites, Mater. Lett., 2003, 57, p 3179

34. Y.J. Liang and Y.C. Che, Thermodynamic Data Handbook of Inorganic Substances, Northeastern University Press, Shenyang, 1994, p 328

35. Z. Mei, Y.W. Yan, and K. Cui, Effect of Matrix Composition on the Microstructure of In Situ Synthesized TiC Particulate Reinforced IronBased Composites, Mater. Lett., 2003, 57, p 3179

36. I. Barin, O. Knacke, and O. Kubaschewski, Thermochemical Properties of Inorganic Substances, Springer, Berlin, 1977, p 257-258 